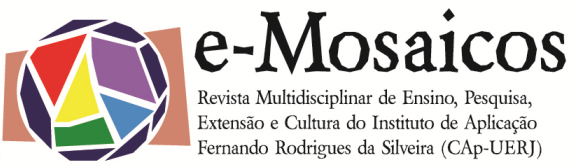

\title{
DIVERSIDADE, ESCOLA E PRÁTICAS DOCENTES: APRESENTANDO A EDIÇÃO
}

A sexta edição da e-Mosaicos se inicia com o artigo encomendado, de autoria de Angélica Maria Reis Monteiro, da Universidade do Porto, intitulado Mind the digital gap: ambientes digitais inclusivos como dispositivos pedagógicos. Este artigo possibilita ao leitor refletir sobre os ambientes digitais como promotores de inclusão digital e considera tais ambientes como favorecedores de inclusão nas práticas pedagógicas. A sessão Artigos é composta de cinco outras produções que refletem a diversidade e a multidisciplinaridade que compõe a e-Mosaicos. O primeiro texto, de autoria de Denise Brasil Alvarenga Aguiar e de Mariana da Costa Valim, intitulado Tensões da modernidade brasileira: pelas searas de Jorge Amado, discute as ambiguidades e tensões da modernidade ao dialogar com a obra Seara Vermelha, de Jorge Amado. Nilzelene Imaculada Lucindo e Regina Magna Bonifácio Araújo, autoras de Nas narrativas dos pedagogos, um retrato de suas condições de trabalho, apresentam estudo sobre as condições de trabalho de pedagogos de instituições de ensino público da Superintendência Regional de Ensino de Ouro Preto/MG. Consideram para tal estudo pesquisa bibliográfica e relatos. Alimentos funcionais e nutracêuticos: uma proposta de educação nutricional a partir do ensino de bioquímica, de Thiago José Jesus Rebello e outros autores objetiva alocar o estudante como protagonista da produção do saber, da experimentação e divulgação tendo como foco a educação nutricional a partir do ensino da bioquímica. O quarto artigo, intitulado A relevância de recursos didáticos no ensino de Sociologia da educação básica: exemplos de experiências no Colégio Pedro II, de Wallace Ferreira, faz referência às experiências pedagógicas bem sucedidas nas aulas de Sociologia oferecidas ao Ensino Fundamental no Colégio Pedro II, tendo como recorte os anos de 2011 a 2013. Esta sessão se encerra com artigo de autoria de Andrea da Paixão Fernandes, intitulado Jovens, escola e trabalho: significados e sentidos atribuídos, que considera os sentidos atribuídos por jovens estudantes da modalidade Educação de Jovens e Adultos às suas trajetórias escolares e também analisa a relação estabelecida por esses jovens com o mundo do trabalho e com os fluxos de entrada e de saída da instituição formal de ensino. Esta edição se encerra com a resenha escrita por Mara Monteiro Cruz apresentando o livro Novas trilhas no modo de fazer pesquisa em educação especial, organizado por Leila Regina d'Oliveira de Paula Nunes e publicado em 2014 pela Editora Marquezine \& Manzini e ABPEE.

Boa leitura!

Andrea da Paixão Fernandes Débora de Aguiar Lage Conselho Editorial 